\title{
Aspects of critical thinking in ballroom dance education
}

\author{
S. Nabatov ${ }^{1}$, O. Mankovska ${ }^{2}$ \\ ${ }^{1}$ Department of Foreign Philology, Faculty of Linguistics and Social Communications, National Aviation University, Brooklyn Institute, \\ New York University (USA), Kyiv, Ukraine \\ ${ }^{2}$ Department of Psychology and Pedagogy in Education, Department of performing arts, Kyiv International University, Kyiv, Ukraine, \\ Corresponding author. E-mail phd01501@gmail.com, https://orcid.org//0000-0001-6844-0473, ovatsiya15@ gmail.com, https://or- \\ cid.org//0000-0002-6022-1628
}

Paper received 11.01.21; Accepted for publication 29.01.21.

https://doi.org/10.31174/SEND-PP2021-245IX96-08

\begin{abstract}
In today's socio-economic conditions, a specialist who responds to new social expectations, a mobile, capable of artistic growth and professional self-improvement, updating his knowledge, professional theory and practice, can use media and modern information technologies, effectively works. The scientific and pedagogical literature analysis made it possible to conclude that certain theoretical aspects need to be clarified and expanded among essential features of critical thinking development despite the published works on the outlined problem. The eighties witnessed a growing accord that the heart of education lies exactly where traditional advocates of a liberal education always said it was -- in the processes of inquiry, learning, and thinking rather than in the accumulation of disjointed skills and senescent information. By the decade's end, the movement to infuse the K-12 and post-secondary curricula with critical thinking (CT) had gained remarkable momentum [1].
\end{abstract}

Keywords: critical thinking; creativity; dance training; skills; academic environment.

Purpose. To analyze the essence of critical thinking development in students while obtaining dance education, types, and physiological and psychological aspects of this process.

Methods. Analysis, synthesis, comparison, generalization, and systematization of psychological and pedagogical literature on critical thinking and its activity aspect in domestic and foreign theory; the forecasting method to specify the value of theoretical elements of the critical thinking development by future specialists in theatrical art.

The dance studio instructor would need to teach beginner class students some basic understanding of dancing without an immediate connection to biology, human anatomy, physiology, and kinesiology. Yet some well-known movement principles are there to study and use in dancing and developing critical thinking in Dance.

Symmetry: The use of the two sides of the body (right vs. left side, arm, leg), etc., both in position and while moving. The ability to do the same thing simultaneously or sequentially using both sides.

Each Movement Principle also includes the opposite. Playing with asymmetry and isometry is included in this principle.

Directionality: The awareness of body orientation in space. Usually, this is derived from the position of hips and torso, but interesting postures might arise from the various directions of each body part in

relation to space, e.g., the audience, the camera, the studio.

Balance: The ability to stand and move in balance or out of balance. It depends on whether the line of gravity falls within the line of your supporting limb(s) or not. The awareness of the different vector

forces on your body.

Alignment: The awareness of the body's geometry, the axes (sagittal, horizontal, vertical), and planes. The relations of different body parts and joints create "lines" in the body shape.

Weight-bearing vs. Gesturing: This principle is about the difference between a movement concerned with bearing weight (weight transference, stepping) and a movement (gesture) that does not carry weight but has intention/expression.

Gross vs. Fine Motorics/Isolation/Articulation: The ability to distinguish small movements done by specific body parts, e.g., hand or one hip, or one shoulder, without moving the rest of the body, vs. moving larger parts of the body as a whole.

Coordination: One of the essential skills practiced in every kind of dancing is synchronizing or not different parts of the body that can move in the same or separate tempos.

Motion through Space: Progressing through space or towards particular directions, paths, etc. "Moving through space vs. dancing on the spot. Also, the body as the moving point in space or as continuously changing moving volume.

Rhythm and phrasing. The ability to move in particular (predefined or improvised) rhythms. This principle is also about how the dancer's movement is related to the music and its rhythmical aspects (tempo, time signature, rhythmic patterns, etc.).

Stillness. While movement seems to be the essence of Dance, a dancer needs to improve her/his ability to remain still, whether this is a part of choreography or interpretation of rhythmical pauses, and exercise for balance and body isolation parts. Stillness is usually connected to the notion of being present.

Dance science teaching methodology involves integrating three forms of knowledge:

Declarative,

Procedural,

Metacognition.

In recent decades, the problem of enhancing critical thinking skills in college students examined extensively. Dance science content and goals are similar to many subject areas where a breadth of information must be mastered and problem-solving will be required. Developing competencies that will enable dancers to become more knowledgeable about their dance training and ultimately exercise well-informed judgments in their teaching will involve the integration of three kinds of knowledge used in critical thinking processes:

1. Declarative knowledge, knowing the facts and concepts of the discipline.

2. Procedural knowledge, learning how to reason, inquire, and present knowledge in the discipline.

3. Metacognition, cognitive control strategies such as setting goals, determining when additional information is 
needed, and assessing a line of inquiry's fruitfulness. [2]

Several learning principles summarize the different teaching styles applied to different practices:

Mimesis: imitation/copying instructor teaches the student a specific movement or sequence of actions, and the student follows the training. It is a case where the learning is based mainly on the students' observational abilities as they should see and do.

Generative: the teacher gives the student an exercise/phrase/sequence as a starting point to achieve technical and creative goals. In this case, the student is allowed to generate new kinetic material or alter things as long as they are consistent with the technical or creative goals.

Reflexive: the student is given a movement task/image/to work with, improvising without trying to achieve a specific phrase/sequence, and the teacher provides feedback. If the student's memorization ability is challenged, as in contrary to the mimetic approach, one has to remember the sequence, rather than see and do, and at the same time is allowed to alter or generate new material, as in the generative approach.

Traditional: also known as "command style teaching": where the teacher makes all the decisions, and the learner follows. The teacher "commands" what the student must correct or change to achieve the movement's excellent performance. The method requires precision and accuracy of execution.[3]

With all that in mind, there is the route of teaching dance, which uses every teaching principle in a specific stage of dancer development.

At the beginning of the non-dancer transformation to a beginner skills level performer, the traditional teaching style required. Paulo Freire critiques the conventional educational system through what he calls the banking model of education - students are likened to a bank. The teachers make deposits for students to receive, memorize, and repeat information and are passive participants in their learning instead of active participants. The information that was provided by teachers was considered to be "absolute information" that could not be questioned, preventing students from gaining critical consciousness to challenge the inherently oppressive nature of education. According to critical pedagogy theory, the product of education is politically subjective information placed under the guise of objectivity. It must be vetted, with teachers acting as the facilitators towards a pursuit of 'new knowledge [4].

But the "banking model of education" is needed to boost a two left-foot person to start his or her dance transformation. At the later stages of dance education, reflective, generative, and mimesis teaching principles will activate students' critical and creative thinking.

Ballroom dance is considered to be a formal social dance, which couples tend to indulge in. However, ballroom dance is more than a couple's activity. Ballroom dance also involves cognitive functions. For instance, Weiyun Chen and Theresa Cone describe how people use critical thinking skills to execute particular movements. The definition of critical thinking based on The Foundation for Critical Thinking suggests that it "is that mode of thinking - about any subject, content, or problem - in which the thinker improves the quality of his or her thinking by skillfully analyzing, assessing, and reconstructing it. It is self-directed, self-disciplined, self-monitored, and self-corrective thinking." [5] Critical thinking during the learning process helps us skillfully analyze the type of music and the number of beats that it entails. It is the process of ac- cessing a more profound capacity for thinking and remembering that aids us in keeping track of our dance steps during a song. It is a constant, nonstop display of precise actions and fluid movements with our dance partner. Critical thinking allows the person to gather and assess relevant information quickly with more proficiency. People will interpret the actions differently, but ultimately the results will usually be the same. By applying every principle of the movement described above, we can communicate with our bodies to relay the next message to our partner through body language. Ballroom dance is a duet dancing, in which the man will be leading the lady. He will be communicating the next step and movements. In many cases the man may improvise his steps. Both partners must stay active as to what the other is saying through their body language to determine the next few steps without making a mistake during the performance. Their minds must remain active and pay close attention throughout the entire process. Furthermore, some neuroscientist believes that this could be due to two mechanisms. First is the central nervous system (CNS), composed of the spinal cord and brain. While the second is the peripheral nervous system (PNS). The PNS is composed of the peripheries and everything else in the body. Both the CNS and the PNS work in concert with one another, as normal brain function is needed to efficiently operate a human body. Therefore, the PNS and CNS are essential for critical thinking, a necessary attribute for performing dance movements.

To be a successful dance performer and competitors require a particular level of critical thinking. Critical thinking is the objective analysis and evaluation of an issue [6] to form a judgment. Such skills are evident when both partners are dancing together, as they usually think about the movements that they must execute.

Critical thinking in correlation to dance helps to express feelings, ideas, and thoughts through physical manifestation. For instance, critical thinking helps us become adept at analyzing the type of music and the variety of beats in concert. Critical thinking is also needed to execute the proper dance moves in correlation to each dance routine. Furthermore, when people perform dance moves, they usually count the number of steps or beats in their heads. For example, the tango's basic steps require two slow steps, followed by two quicks steps (slow, slow, quick, and quick). After that, the dance partners usually think about what comes next. The next step to the Dance is a few rock steps followed by a Promenade, etc. Correspondingly, this means that the people who participate in such dances will have to think about many dance steps before making them until the dancer becomes more proficient in their area of expertise. When a person does become skilled in a particular dance, they will not have to think much about executing moves anymore. It is due to muscle memory, which can reproduce a precise movement without conscious thought. Muscle memory is acquired as a result of frequent repetition of that specific movement.

Critical thinking is most crucial when one is learning new things, especially dance processes. It is due to synaptic pruning, which is how extra neurons and synaptic connections are eliminated. It happens to increase the efficiency of neuronal transmissions. In other words, the brain eliminates neurons that are not used regularly. It does this to strengthen the neurons that are more commonly used. It is a good thing, as it helps one become an expert in their area of practice. Furthermore, the central nervous system (CNS) is essential for the 
beginning phases of synaptic pruning. It is because one must use more neuronal activity when first learning something new.

Additionally, this is especially important when learning dance moves (Weiyun et al., 2003). People also have opportunities to manipulate the movement elements, which translate their ideas into dance sequences. Moreover, critical thinking helps to create dance movements, sequences and to make movements more expressive. For instance, they have to concentrate on a movement task, generate movement possibilities, and refine dance sequences. Correspondingly, all of this is possible because of the high activation of the CNS (Weiyun et al., 1996).

People engage in their critical thinking capabilities to develop a deeper understanding of the Dance learned. It is instrumental for people because it helps build individuals' cognitive, affective, and psychological attributes (Chen, 1998). However, critical thinking is also crucial for developing memories. For example, when someone is learning a new activity like dancing, they must think critically. After that, they integrate their thoughts into their short-term memory (STM). Short-term memory is the capacity for holding small amounts of information. When the human body integrates memory into STM, it puts the remaining knowledge into long-term memory (LTM). Long term memory is the stage in which informative knowledge is held indefinitely. Correspondingly, this is true for both implicit and explicit memory, which are essential for dancing. Implicit memory is a long-term memory, which is acquired and used unconsciously. One of the forms of implicit memory is procedural memory. For example, a professional dancer should execute many advanced dance moves without much thought, in opposition to explicit memory, which is the conscious, intentional recollection of factual information. For instance, a new dancer is more likely to use explicit memory. With that being, both explicit and implicit memories are crucial critical thinking. Therefore, critical thinking is a crucial component of Dance.

Ballroom dance is a formal social dance, which couples tend to participate in. It is the general perspective that society has of this exquisite form of Dance. Nevertheless, one could argue that ballroom dance is more than a couple's activity. They could illuminate that ballroom dance also involves neural activity. For instance, Weiyun Chen and Theresa Cone describe how people use critical thinking skills to perform particular movements in correlation to dance.
Moreover, some neuroscientist believes that this could be due to two things. First is the central nervous system (CNS), composed of the spinal cord and brain. While the second is the peripheral nervous system (PNS). The PNS is composed of the peripheries and everything else in the body and is crucial for dancing. It is due to the PNS interchangeably linked to muscle memory associated with implicit memory. Simultaneously, explicit memories are more connected to the CNS, as it requires more thought. Overall, both the CNS and the PNS work in association with one another. It $\mathrm{s}$ is due to normal brain function being a prerequisite for making the body operate efficiently, which is vital for executing dance movements. Therefore, the PNS and CNS are essential for critical thinking and are essential for performing dance movements.

Fig. 1.

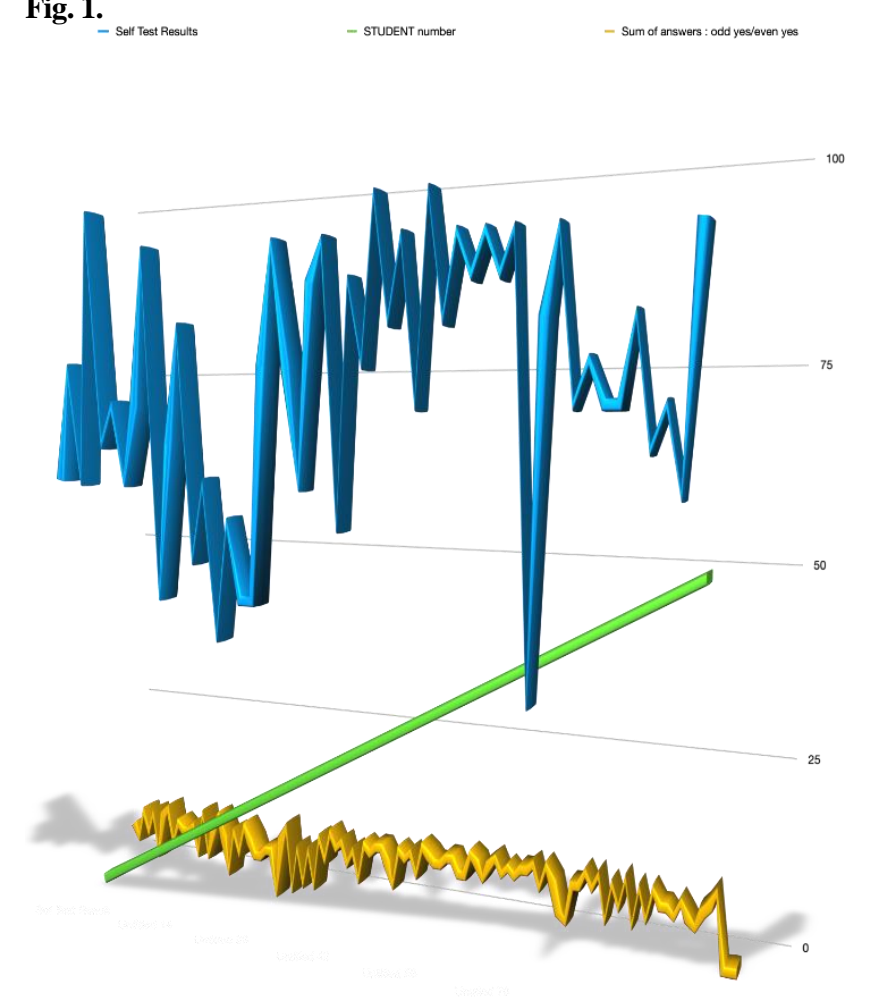

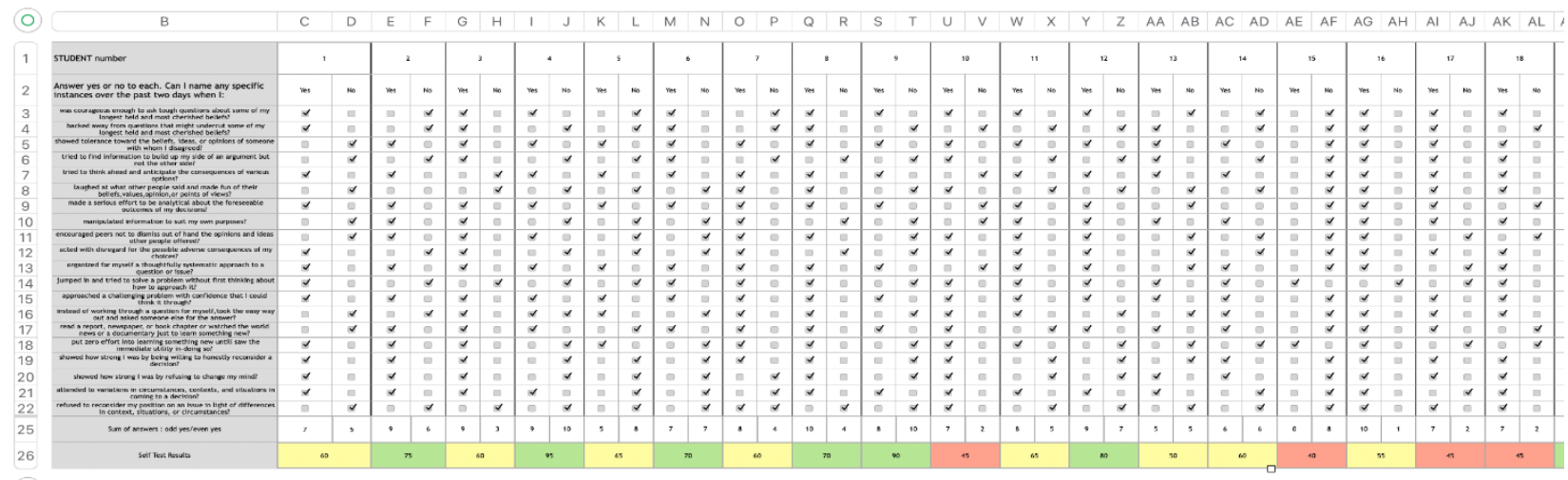

Table 1.

Results. The thinking types include concrete and abstract, intuitive and discursive, visual-figurative, and conceptual (conceptual, systemic). Critical thinking is understood as argumentative analysis, problem-solving, decision-making, and 
an in-depth self-motivated cognitive process. Found that critical thinking has the following stages:

To identify the problem.

To select the relevant information.

Information analysis.

Search for the reasons causing the problem.

Generate ideas.

Formulate questions for verifying conclusions and ideas.

Choose the most effective solution.

Implement the solution and test it.

The physiological-psychological aspects of critical thinking include memorization, understanding, application, analysis, evaluation, creation.

To be a good dancer, students need to memorize steps and many other necessary components. Put that all together and practice solo and with the partner. Advancing the higher level required a critical and creative approach to mastering dance, preparing students for future opportunities as performers. The self-test evaluation conducted with the students of the beginner ballroom dance course shows that most participants need to improve their level of critical thinking.

Originality. Based on the analysis of scientific literature in the retrospective attempt to determine the essence and peculiarities of critical thinking for the professional training of specialists from different fields; the analysis of the importance of critical thinking for future ballroom dance performers was made, and the stages of the development of critical thinking in the educational process for ballroom dancing were determined.

Conclusion. The analytical review of developing critical thinking in Dance shows that critical thinking is the staged implementation of actions from simple to complex: memorization, understanding, application, analysis, evaluation, creation. The critical thinking development in future art performers, dancers, or theater artists is an integral aspect of their professional training and requires a more thorough study.

\section{Attachment}

Critical Thinking Mindset Self-Rating Form Answer yes or no to each. Can I name any specific instances over the past two days when I: was courageous enough to ask tough questions about some of my longest-held and most cherished beliefs?

backed away from questions that might undercut some of my longest-held and most cherished beliefs?

showed tolerance toward the beliefs, ideas, or opinions of someone with whom I disagreed

tried to find information to build up my side of an argument but not the other side?

5. tried to think ahead and anticipate the consequences of various options?

6. laughed at what other people said and made fun of their beliefs, values, opinion, or points of view?

7. made a serious effort to be analytical about the foreseeable outcomes of my decisions?

8. manipulated information to suit my purposes?

9. encouraged peers not to dismiss out of hand the opinions and ideas other people offered?

10. acted with disregard for the possible adverse consequences of my choices?

11. organized for me a thoughtfully systematic approach to a question or issue?

12. jumped in and tried to solve a problem without first thinking about how to approach it?

13. approached a challenging problem with confidence that I could think it through?

14. instead of working through a question for myself, took the easy way out and asked someone else for the answer?

15. read a report, newspaper, or book chapter or watch the world news or a documentary to learn something new?

16. put zero effort into learning something new until I saw the immediate utility in doing so?

17. showed how strong I was by being willing to reconsider a decision honestly?

18. showed how strong I was by refusing to change my mind?

19. attended to variations in circumstances, contexts, and situations in coming to a decision?

20. refused to reconsider my position on an issue in light of differences in context, situations, or circumstances?

Give yourself 5 points for every "Yes" on odd-numbered items and every "No" on even-numbered items. If your total is 70 or above, you are rating your disposition toward critical thinking over the past two days as generally positive. Scores of 50 or lower indicate a self-rating opposed or hostile toward critical thinking over the past two days. Scores between 50 and 70 show that you would rate yourself as displaying an ambivalent or mixed overall disposition toward critical thinking over the past two days.

If you have described yourself honestly, this self-rating form can offer a rough estimate of what you think your overall disposition toward critical thinking has been in the past two days.

(C) 2009 Measured Reasons LLC, Hermosa Beach, CA. USA www.measuredreasons.com Used with Permission.

(C) 2016, Measured Reasons LLC 3 | Page PO Box 879, Redondo Beach, CA 90277 USA www.measuredreasons.com pfacione@measuredreasons.com Phone (650) 743-8632

\section{REFERENCES}

1. The Delphi Report" Dr. Peter A. Facione,

American Philosophical Association Delphi Research Report EPIC Doc.No.: ED 315423

https://www.qcc.cuny.edu/SocialSciences/ppecorino/CT-Expert-Report.pdf

2. Kurfiss J, 1988, p. iv. 35. Cross KP, Steadman MH: Classroom Research: Implementing the Scholarship of Teaching. San Francisco: Jossey-Bass Inc., 1996, p. 41. Cross KP, Steadman MH, 1996, p. 43.

3. MOCO'16, July 05-07, 2016, Thessaloniki, GA, Greece ACM 978$1-4503-4307-7 / 16 / 07$. http://dx.doi.org/10.1145/2948910.2948912

4. Freire, Paulo (2006) [1970]. "The banking model of education". In Provenzo, Eugene F. (ed.). Critical issues in education: an anthology of readings. Thousand Oaks, CA: Sage Publications. pp. 105117. ISBN 1412936551. OCLC 62324920.)
5. Chen, W., \& Cone, T. (2003). Links Between Children's Use of Critical Thinking and an Expert Teacher's Teaching in Creative Dance.

Article in the Journal of Teaching in Physical Education January 2003 DOI: $10.1123 /$ jtpe.22.2.169

6. https://www.coursehero.com/file/16494331/Critical-thinking-isthe-objective-analysis-and-evaluation-of-an-issue-in-order-toform-a-judgmentd/)

7. Chen, W. (2001, November 4). Description of an Expert Teacher's Constructivist-Oriented Teaching: Engaging Students' Critical Thinking in Learning Creative Dance. DOI: 10.1080/02701367.2001.10608973

8. Pamela Matt (2003) "Critical Thinking" in Dance Science Education, Journal of Dance Education, 3:4, 121-130, DOI: 10.1080/15290824.2003.10387245 